\title{
Heart Rot of Pomegranate: Disease Etiology and the Events Leading to Development of Symptoms
}

David Ezra, Benny Kirshner, Michal Hershcovich, and Dani Shtienberg, Department of Plant Pathology and Weed Research, Agricultural Research Organization, the Volcani Center; and Itzhak Kosto, Extension Service, Ministry of Agriculture and Rural Development, Bet Dagan, 50250 Israel

\begin{abstract}
Ezra, D., Kirshner, B., Hershcovich, M., Shtienberg, D., and Kosto, I. 2015. Heart rot of pomegranate: disease etiology and the events leading to development of symptoms. Plant Dis. 99:496-501.

Pomegranate fruit rot disease, known as "heart rot" or "black heart," is a major pomegranate disease that impacts production worldwide. Heart rot is characterized by black rot of the fruit core that spreads from the calyx area, whereas the outer peel and the hard rind retain their healthy appearance. Aims of the present study were to identify the pathogen that causes pomegranate heart rot in Israel and to study the dynamics of fruit-organ colonization by fungi during fruit development, as the first steps toward the development of management strategies. Several fungi were isolated from pomegranate fruits, among which were species of Penicillium, Aspergillus, Botrytis, and Rhizopus, but the causative pathogen of the disease was identified as Alternaria alternata. This fungus was isolated from the pistils of more than $85 \%$ of open flowers and $\sim 20 \%$ of the

loculi of asymptomatic fruits and from all tissues of the symptomatic fruits. The dynamics of fruit-organ colonization by fungi during fruit development was recorded in six commercial orchards in 2010 and 2011. It was found that $A$. alternata spores germinate on the stigmata of open flowers and develop into the style. In some fruits, the mycelium grows into the tunnel and reaches the lower loculus, where the fungus becomes latent for about 3 to 4 months pending initiation of fruit ripening. Then, in a small number of fruits, the fungus starts growing and invades the arils, causing black rot of the arils in the lower loculus. At the beginning of disease development, the fungus causes brown soft rot of the arils, which becomes black and dry as the fungus grows. Eventually, the fungus grows from the lower loculus into the upper loculi, causing rot of the entire fruit.
\end{abstract}

Pomegranate (Punica granatum L., Punicaceae) is an ancient plant and fruit native to central Asia. The plant is a multitrunk shrub with bushy appearance, which under domestication is grown as a tree up to $5 \mathrm{~m}$ in height (Levin 2006), of which most varieties are deciduous. Because the pomegranate tree is highly adaptive to a wide range of climatic and soil conditions, it is grown in many different geographical regions including the Mediterranean basin, Asia, and California (Holland et al. 2009). Pomegranate fruit may be consumed as fresh fruit, juice, or wine; currently, separated arils are sold as a product in supermarkets.

Growing awareness of the medical and health benefits of the pomegranate fruit has stimulated a sharp increase in consumption of the fruit and juice and, as a result, there has been significant growth in orchard planting worldwide. New orchards have been planted in the traditional growing regions, in California, and in the southern hemisphere in South America, South Africa, and Australia (Day and Wilkins 2009; Holland et al. 2009). Recent scientific findings indicate that tissues of the pomegranate fruit, flowers, bark, and leaves contain bioactive phytochemicals that are antimicrobial, reduce blood pressure, and are active against serious diseases such as diabetes and cancer (Seeram et al. 2006). Among pomegranate's longest known health benefits are its activities against infectious diseases (Jayaprakasha et al. 2006), and antimicrobial activity of pomegranate extracts has been demonstrated against a wide array of bacteria, fungi, and viruses (Jayaprakasha et al. 2006).

In Israel, until the year 2000, pomegranate was considered a minor crop grown on about 150 ha. However, as a result of research emphasizing the health benefits of the fruit, the extent of tree planting rose dramatically: with the addition of new varieties, it stood at 400 ha by 2004, and by 2013 the extent of plantations was estimated at 2,700 ha.

Corresponding author: David Ezra, E-mail: dezra@ volcani.agri.gov.il

Accepted for publication 10 October 2014.

http://dx.doi.org/10.1094/PDIS-07-14-0707-RE

(C) 2015 The American Phytopathological Society
Annual production is about 60,000 tons of fresh fruit, of which about $50 \%$ is exported. The main varieties grown in Israel are: 'Wonderful' (red, sweet-sour, occupying about $80 \%$ of the production area); 'Emek,' 'Akko,' and 'Shani' (pink and red, sweet, early ripening varieties, occupying about $12 \%$ of the production area); and ' 116 ,' 'Hershkowitz,' and 'Camel' (red, sour, occupying about $8 \%$ of the production area) (Israeli fruit board and I. Kosto, personal communication). Flowering usually begins at the beginning of May-June. Fruit set and growth lasts until the end of the summer (August for the early varieties 'Emek,' 'Akko,' and 'Shani;' September for '116,' 'Hershkowitz,' and 'Camel;' and October for 'Wonderful') (Holland et al. 2009 and I. Kosto, personal communication).

Pomegranate fruit rot disease, known as "heart rot" or "black heart," is a major pomegranate disease that impacts production worldwide (Day and Wilkins 2009; Holland et al. 2009; Pala et al. 2009; Tziros et al. 2008). When infected fruits are opened, brown (soft) to black (dry) rot of the arils is observed. Nevertheless, the outer peel and the hard rind of infected fruits retain their healthy appearance (Tziros et al. 2008). Fruits with heart rot can be identified in the orchard according to their skin color and their light weight; furthermore, when such fruits are knocked, they emit a hollow sound, in contrast to the dull sound from healthy fruits. There is, at present, no effective control in the orchard and in many cases, healthy-looking fruits develop the disease in storage. Fruit loss may be substantial, as was reported, for example, from California (Zhang and McCarthy 2012) and Greece, and may cause significant damage of up to $50 \%$ of the fruits in the orchards (Tziros et al. 2008). However, one long-term damaging effect of the disease concerns the quality of the product and its reputation and a single diseased fruit purchased by a consumer might cause individual and his relatives to reject consuming pomegranate fruits for years to come. Another problem can arise in industry where a diseased fruit entering a juice or fresh aril production process might cause spoilage or delay production.

In most cases, Alternaria spp. and Aspergillus spp. were isolated from diseased pomegranate fruits (Michailides et al. 2008). Other fungi (such as Penicillium sp., Botrytis sp., and Rhizopus sp.) were also isolated. Accordingly, it is not always clear which is/are the causal agent(s) of the disease and what is the role of the other fungi 
in the disease syndrome. It is generally accepted that the infection of fruits occurs in the orchard during flowering (Zhang and McCarthy 2012; Ezra, unpublished data), but experimental data addressing the infection process and disease development in the fruit are currently unavailable. Alternaria alternata (Fr.) Keissl. may also infect other tissues of the pomegranate tree (Ezra et al. 2010; Pala et al. 2009; Tziros et al. 2008). In Turkey, A. alternata caused lesions on leaves, flowers, and young fruits (Pala et al. 2009). Recently, we reported on the appearance of novel symptoms of A. alternata infection in pomegranate orchards in Israel (Ezra et al. 2010; Gat et al. 2012): black spots on leaves and fruit surface, as well as chlorosis, and abscission of some leaves. On fruits, the damage was restricted to the peel surface, with the edible tissue remaining unaffected. This disease was later reported from Spain and Egypt as well (Ammar and El-Naggar 2014; Berbegal et al. 2014).

Two main scenarios represent possible descriptions of heart rot development in the orchard. According to the first scenario, a spore penetrates the pistil of an open flower and grows into the tunnel (an opening connecting the pistil to the loculus) and then into the loculus, where it remains latent until the ripening fruit can support its growth. Later, it resumes its growth in the lower loculus, causing rot of the arils as it grows into the upper loculus and eventually infects the entire fruit. According to the second scenario, the infection of the pistil occurs at some point in the course of fruit growth. The spore then germinates, penetrates the pistil, grows through the tunnel into the lower loculus, and causes rot of the arils as it grows into the upper loculus, eventually infecting the entire fruit. If the first scenario is correct, it should be possible to isolate the rot-causing fungus from the pistil, tunnel, and loculus at all fruit-development stages, from flower opening to fruit ripening. However, according to the second scenario, it should not be possible to isolate the fungus from any of the fruit parts during the first few stages of fruit development, but during later stages of development the isolation of the fungus increases abruptly and then remains steady until fruit ripening. Our research hypothesis was that identifying the causal agent of the heart rot disease and determining the chain of events leading to development of symptoms within the fruits would enable us to formulate concepts applicable to the disruption of these processes. This would lead, in turn, to development of means for disease suppression, prevention of yield losses, and improvement of the quality of pomegranate products. The specific objectives of the present study were: (i) to identify the pathogen that causes pomegranate heart rot in Israel, and (ii) to study the dynamics of fruit-organ colonization by fungi during fruit development.

\section{Materials and Methods}

Fungal isolation, identification, and pathogenicity tests. Fruits suspected to be diseased and fruits that were presumed healthy (35 fruits from each group) were collected in 2009 from commercial pomegranate orchards, starting one month before ripening (Table 1). Suspected fruits exhibited the following symptoms: discoloration (redness) of one part of the fruit; emission of a hollow sound when knocked, in contrast to the dull sound from healthy fruits; easy release from the tree when picked; light weight; and in some cases, a rugged peel. The fruits were taken to the laboratory, surfacesterilized in 3\% sodium hypochlorite solution for $1 \mathrm{~min}$, and rinsed twice in distilled water. The fruits were cut with a sterile knife and then divided into two groups: those that exhibited any internal symptoms (such as discoloration or rot) and those that were asymptomatic. Rotten aril tissues from inside the fruit were placed

Table 1. Details of the orchards from which fruits were sampled in this study

\begin{tabular}{|c|c|c|c|c|}
\hline Village & Latitude & Longitude & Cultivar & Sampling season \\
\hline \multirow[t]{3}{*}{ Kidron } & $\mathrm{N} 31^{\circ} 49^{\prime} 13.44^{\prime \prime}$ & E34 $44^{\circ} 48^{\prime} 4.32^{\prime \prime}$ & Wonderful & $2009,2010,2011$ \\
\hline & $\mathrm{N} 31^{\circ} 49^{\prime} 13.44^{\prime \prime}$ & $\mathrm{E} 34^{\circ} 48^{\prime} 4.32^{\prime \prime}$ & 116 & 2009,2010 \\
\hline & $\mathrm{N} 31^{\circ} 49^{\prime} 39.36^{\prime \prime}$ & E34 $44^{\circ} 20.64^{\prime \prime}$ & Akko & 2011 \\
\hline Givat Nili & $\mathrm{N} 32^{\circ} 32^{\prime} 51.36^{\prime \prime}$ & $\mathrm{E} 35^{\circ} 02^{\prime} 45.6^{\prime \prime}$ & Wonderful & 2009, 2010, 2011 \\
\hline Amikam & $\mathrm{N} 32^{\circ} 34^{\prime} 35.04^{\prime \prime}$ & $\mathrm{E} 35^{\circ} 02^{\prime} 19.68^{\prime \prime}$ & 116 & $2009,2010,2011$ \\
\hline Ein Iron & $\mathrm{N} 32^{\circ} 29^{\prime} 44^{\prime \prime}$ & $\mathrm{E} 35^{\circ} 01^{\prime} 27.84^{\prime \prime}$ & Akko & 2011 \\
\hline
\end{tabular}

on potato dextrose agar (PDA) (Acumedia, Lansing, MI) amended with tetracycline (Sigma, Rehovot, Israel) at $12 \mu \mathrm{g} \mathrm{ml}^{-1}$; the plates were incubated at $25^{\circ} \mathrm{C}$. Mycelium from fungal colonies was transferred to new plates and left to grow for 5 to 7 days prior to macroscopic and microscopic identification. Single-spore fungal isolates were prepared and used in the artificial inoculation experiments. As comparable symptoms were observed in all orchards and for the two varieties tested, data presented in this report were pooled. Healthy looking arils from nonsymptomatic fruits were used for Penicillium isolation as described above.

Koch's postulates with both Alternaria sp. and Penicillium sp. (two independent experiments, using seven different isolates for A. alternata and three isolates of Penicillium sp.) were tested with detached fruits. The fruits were surface sterilized as described above, cut

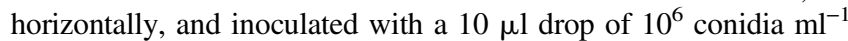
suspension from each isolate. Alternatively, instead of using a spore suspension, a fresh plug of 1-week-old fungal culture grown on PDA was placed in the center of a cut fruit. The inoculated fruits were placed in sealed 1-liter plastic boxes and incubated for 1 week at $25^{\circ} \mathrm{C}$. After symptoms appeared, the fungus was reisolated from infected fruits as described above. Fungi isolated according to Koch's postulates were transferred to new plates and left to grow for 5 to 7 days pending macroscopic and microscopic identification. Additionally, single-spore colonies were used for fungal DNA isolation according to Gat et al. (2012), and were used for amplifying the internal transcribed spacer (ITS)-5.8S rDNA, elongation factor (EF-1, alpha) and glyceraldehyde-3-phosphate dehydrogenase (gpd) sequences. The purified products were sent for direct PCR sequencing (Macrogen, Geumcheon-gu Seoul, South Korea). Sequences were submitted to GenBank and were deposited as accession numbers KC354713, KM052593 to KM052598, KJ830919 to KJ830925, and KJ830926 to KJ830931.

Fruit sampling for disease etiology. During 2010 we collected fruits of two pomegranate varieties-the late-season 'Wonderful' and the early-season ' 116 ' - from the central (Kidron) and the northern (Givat Nili and Amikam) regions of Israel. In 2011, 'Wonderful,' '116,' and an additional variety-the early-season 'Akko'-were collected from Kidron, Givat Nili, and Amikam, and from Ein Iron (Table 1). In each orchard, 20 trees were randomly selected and marked with colored bands. In 2010, flowers and fruits were sampled from each tree every 2 weeks, whereas in 2011, plant organs were sampled at several different growth stages: closed flower, open flower, fruit-bearing, small fruits, and ripe fruits. At each sampling date, the crop developmental stage was recorded according to the $\mathrm{BBCH}$ General Scale (Melgarejo et al. 1997), as follows: $51=$ appearance of flower buds; $55=$ swollen calyx; 61 = open flower; 71 = young fruit; 73 = developing fruit; and $81=$ fruit ripening. One fruit or flower was randomly picked from the perimeter of the tree at each collection time. The samples were surface-sterilized in $3 \%$ sodium hypochlorite solution for 1 min and rinsed twice in distilled water. The flowers or fruits were cut open with a sterile knife, and the pistil was cut into five pieces, which were placed onto PDA amended with tetracycline (Sigma; Rehovot, Israel) at $12 \mu \mathrm{g} \mathrm{ml}^{-1}$ in the same relative positions as in the intact pistil. The same treatment was applied to the fruit tunnel. Arils (at least four) were sampled from the loculi and placed on PDA. The plates were incubated at $25^{\circ} \mathrm{C}$. Mycelium from fungal colonies was transferred to new plates and left to grow for 5 to 7 days pending macroscopic and microscopic identification. All sampled fruits and plates were documented. The percent incidence of colonized pistils, fruit tunnels, and arils for each fruit and the percent incidence of symptomatic fruits were calculated for each sampling date, for each orchard. As similar trends were observed in samples taken from both of the cultivars tested in 2010 and from all three cultivars tested in 2011, the data were pooled. The incidence of colonized or diseased organs ( \pm standard error) was calculated for each sampling date or crop developmental stage.

Data analysis. Statistical analyses were performed using JMP software (SAS Institute Inc.). Means and standard error values were computed for data recorded in 2010 and 2011 for studying the 
dynamics of fruit-organ colonization by fungi. Differences in the incidence of stained and unstained tunnels in symptomatic and asymptomatic pomegranate fruits were determined according to the $\chi^{2}$ test at $P \leq 0.05$.

\section{Results}

Identification of the pathogen causing pomegranate heart rot. In the orchards, fruits with moldy arils could be categorized into two groups according to the symptoms observed on the fruit surface. The first group included fruits exhibiting noticeable external damage on the peel surface-damage that could have resulted from insects invading the mesocarp, rupture of the peel by physical impacts, e.g., a thorn or adjacent branch of the tree, or some other cause. In such cases, fungi had invaded the fruits through the wounds, and rotted arils were scattered in the vicinity of the wounds. Occasionally, symptoms were also visible on the peel surface. For example, the damage presented in Figure 1A is probably due to a mealybug (Pseudococcus maritimus). Damage in the crown enabled penetration of Aspergillus spp. into the fruit, causing rotting of the mesocarp tissue (Fig. 1B); in the case of penetration by Aspergillus spp., no aril rot was observed. These symptoms were not regarded as heart rot. The second group included fruits that did not exhibit any noticeable damage on the peel surface (Fig. 1C); when these fruits were cut, some or all of the arils were rotten and fungal mycelium was observed within the fruits. It should be noted that some of the arils exhibited brown (soft) or black (dry) rot, presumably due to differences in rot development (Fig. 1D). No rotting of the mesocarp was observed in these fruits. In our present study these symptoms were regarded as heart rot.

Developed (suspected and nonsuspected) fruits were collected in the orchards and cut longitudinally through the pistil, which made it possible to view the tunnel leading from the pistil to the lower loculus of the fruit (Fig. 2A). The tunnel remained open until the fruit ripened. Occasionally, fungal mycelia and sporulation were clearly observed on the stamens that remained attached during the advanced stages of fruit development (Fig. 2B). The moldy stamens were located in the vicinity of the stigma and, in some fruits, the inner part of the pistil and the upper portion or the whole of the tunnel were stained. These stained tunnels were either brown or black (Fig. 2C and D), and mycelia were occasionally observed in them (Fig. 2E). Staining of the upper portion of the tunnel was observed in $29.9 \%$ of the asymptomatic fruits, i.e., those in which no rotten arils were observed when the fruit was cut open. In $75.2 \%$ of the symptomatic fruits, rot was restricted to a small number of arils; in $95.4 \%$ of these, the rotten arils were located in the lower loculus, close to the calyx (Fig. 2F). The tunnels of all symptomatic fruits were stained (Fig. 3A). Attempts to isolate fungi from white and discolored tunnels of mature fruits revealed that Penicillium sp. colonized 70 and $75 \%$ of these fruits, respectively, and Alternaria sp. were isolated from 26.9 and $100 \%$ of them, respectively (Fig. 3B).

In the light of macroscopic and microscopic examination of the characteristics of mycelia and spores developing in vitro, the fungus isolated from both soft and dry rotten arils was identified as a species of Alternaria. Several single spore Alternaria cultures were further examined through sequencing of ITS-5.8S rDNA, elongation factor (EF-1, alpha), and glyceraldehyde-3-phosphate dehydrogenase (gpd). All seven isolates used in this study exhibited at least $99 \%$ identity to sequences of $A$. alternata (Nees:Fr.) Keissl available in GenBank. Artificial inoculation of fruits resulted in black rot of the arils, and A. alternata could be reisolated from the rotten arils. All inoculations of detached fruits with Penicillium spp. isolated from the inner parts of fruits collected in the orchards did not result in black typical rot of the arils. In some cases, local collapse of the arils with slight change in aril color (light brown) could be observed in the inoculation site (data not shown). The ITS-5.8S rDNA sequence of a Penicillium isolate used in this study was found to have $100 \%$
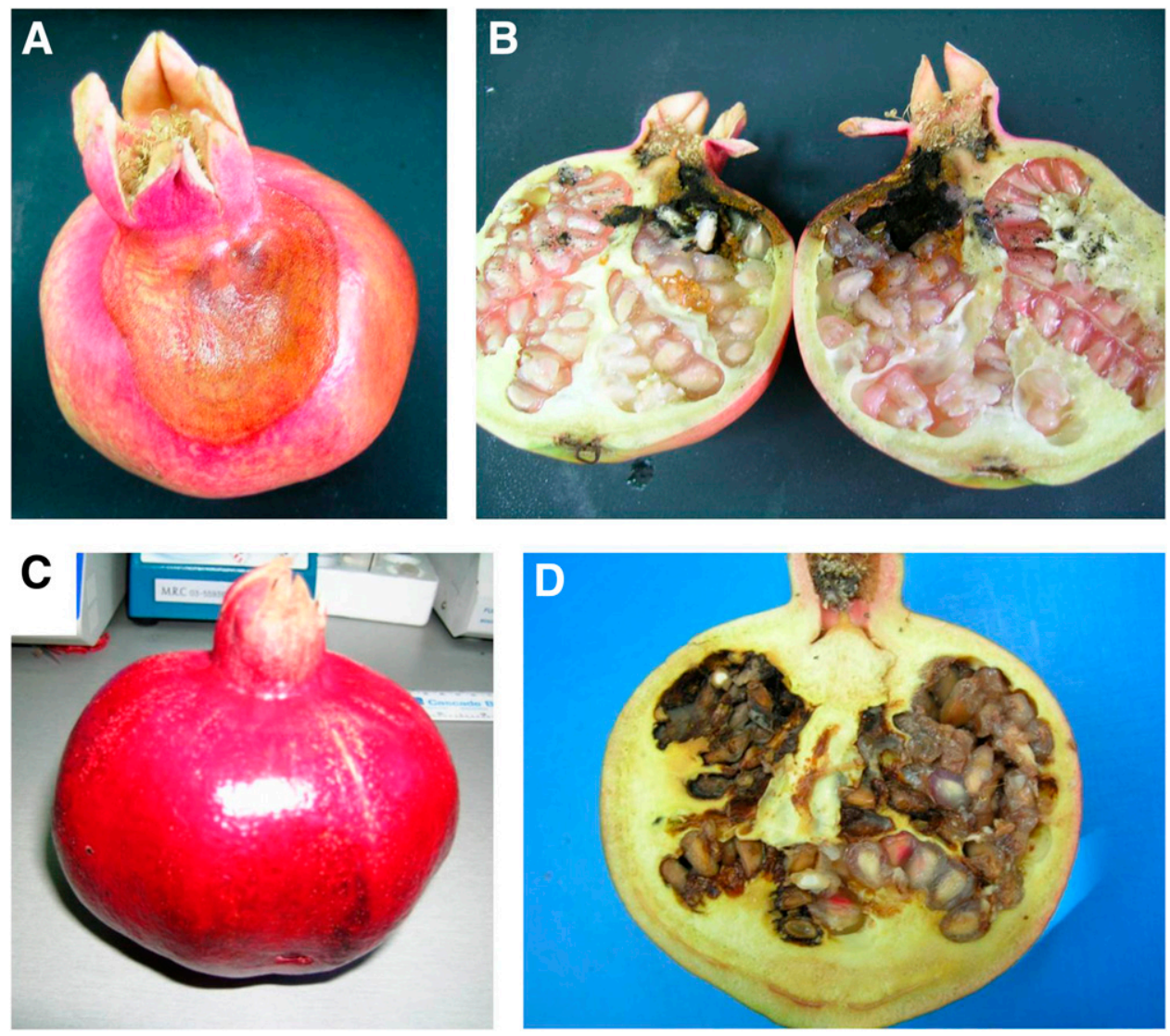

Fig. 1. External and internal symptoms on pomegranate fruits. A and B, Rot caused by Aspergillus sp. It was not considered as heart rot in the present study. C and D, Rot caused by Alternaria alternata; external symptoms were not observed but the internal part of the fruit, including the arils and the inner lamella, exhibited brown (soft) or black (dry) rot. These types of symptoms were considered as heart rot in the present study. 
identity to Penicillium adametzioides. Since the other Penicillium spp. isolated failed to cause fruit rot under laboratory conditions, they were not fully identified to the species level.

The dynamics of fruit-organ colonization by fungi during fruit development. The dynamics of fruit-organ colonization by fungi during fruit development was recorded in 2010 and 2011. In 2010, fungi were rarely isolated from closed flowers (results not shown), but $>75 \%$ of the pistils collected from the early stages of fruit development until maturity were colonized with fungi (Fig. 4A). These fungi were identified as Penicillium spp., Aspergillus spp., A. alternata, Botrytis spp., and Rhizopus spp. Other fungal species were isolated in only a few samples, mainly in the early stages of fruit development, so they were not identified. The incidence of colonized tunnels and loculi was low in the early stages of fruit development, but increased over time. The tunnels and loculi of more than $85 \%$ of the fruits were colonized by fungi (Fig. 4A), with the colonization rate in the former being 10 to $40 \%$ higher than the latter. Two fungi predominated as time progressed: A. alternata colonized the pistils, and Penicillium spp. colonized the tunnels and the loculi (Fig. 4B and C). The proportion of fruits from which Penicillium spp. was isolated from loculi increased gradually with time (and fruit maturity), and was recovered from $87 \%$ of the loculi of mature fruits. On the other hand, colonization of the loculi by A. alternata was sporadic and did not change much as fruit matured. Out of a total of 666 sampled fruits, only 18 (2.7\%) exhibited the typical heart rot symptoms, and out of the 222 fruits sampled from late-July onwards, representing growth stages 73 to 81 , the incidence of symptomatic fruits was $8.1 \%$.

In general, results of the sampling in 2011 resembled those obtained in 2010; the predominant fungi were Penicillium sp. and A. alternata, with the former being more abundant in the tunnels and loculi and the latter in the pistils (Fig. 5). Although $75.8 \%$ of loculi of mature fruits were colonized by Penicillium sp., only $12(2 \%)$ of the sampled fruits exhibited the typical heart rot symptoms. Among the 240 fruits sampled during growth stages 73 to 81 , the incidence of symptomatic fruits was $5 \%$.

\section{Discussion}

The specific objectives of the present study were to identify the pathogen(s) causing pomegranate heart rot in Israel and to study the dynamics of fruit-organ colonization by fungi during fruit development. It was previously reported that the causal agent of heart rot disease of pomegranates was A. alternata (Day and Wilkins 2009; Holland et al. 2009; Tziros et al. 2008; Zhang and McCarthy 2012). In Israel, it was commonly agreed that pomegranate heart rot was caused by a complex of fungi-among which were Alternaria spp. and Aspergillus spp. (Ezra; unpublished data). The present results suggest that in Israel, A. alternata (Nees:Fr.) Keissl is the predominant pathogen causing pomegranate heart rot.

Two main scenarios might describe the dynamics of pomegranate fruit-organ colonization by the pathogen during fruit development. According to the first, spores infect the pistils of open flowers; they grow into the tunnel and then into the loculus, where they remain latent until the fruits reach a ripening stage that supports their development. The pathogen then colonizes the lower loculus, causing rot of
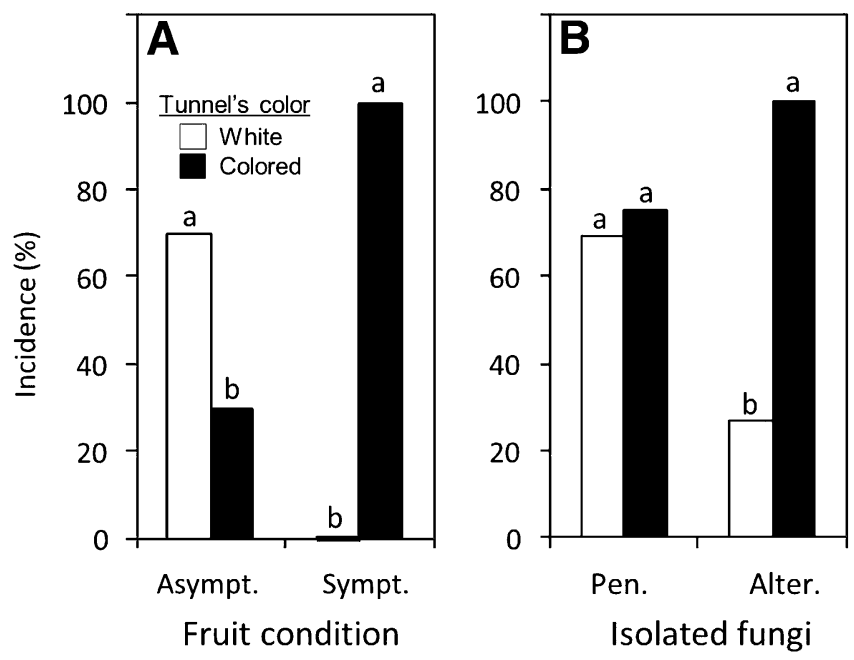

Fig. 3. A, Incidence of unstained and stained tunnels in asymptomatic and symptomatic pomegranate fruits. B, Incidence of fruits with white and stained tunnels, from which Penicillium spp. or Alternaria spp. were isolated. For each group in each graph, values of bars followed by different letters differed significantly at $P \leq 0.05$, according to the $\chi^{2}$ test.
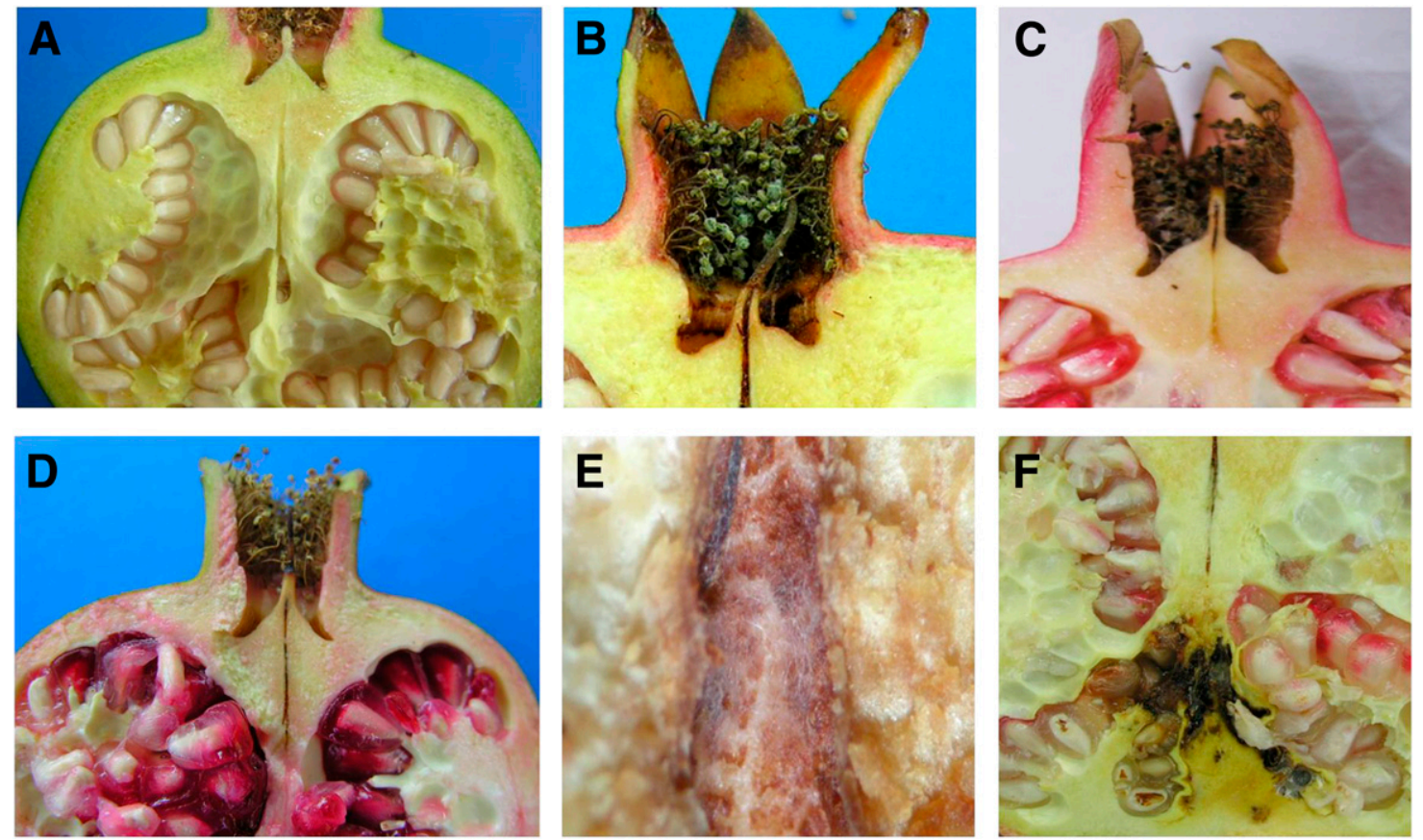

Fig. 2. Longitudinal cuts of asymptomatic and symptomatic pomegranate fruits. A, The tunnel leading from the pistil to the lower loculus of the fruit. B, Mycelia and sporulation of fungi developing on the stamens. $\mathbf{C}$ and D, Discoloration of the inner part of the pistil and the tunnel. E, Mycelia developing in stained tunnels. F, Rot initiation in the lower loculus of the fruit, close to the calyx. 
the arils, and later invades the upper loculi and, eventually, the entire fruit. According to the second scenario, infection of the pistil occurs some time during fruit growth, when the fruit internal environment can support infection and fungal growth. The pathogen develops into the pistil, grows through the tunnel into the lower loculus, where it rots the arils, and then proceeds into the upper loculus, eventually infecting the entire fruit.

Our present results demonstrate that the fruits were infested with A. alternata from flower opening to fruit ripening; this pathogen was isolated from the pistils of more than $80 \%$ of the sampled fruits at all stages from flower opening to fruit ripeness. It was isolated at very low incidence from the tunnels and loculi of asymptomatic fruits, but from all the black tunnels of symptomatic fruits (Fig. 3B). This implies, presumably, that the first of the above scenarios better represents the etiology of pomegranate heart rot in Israel.
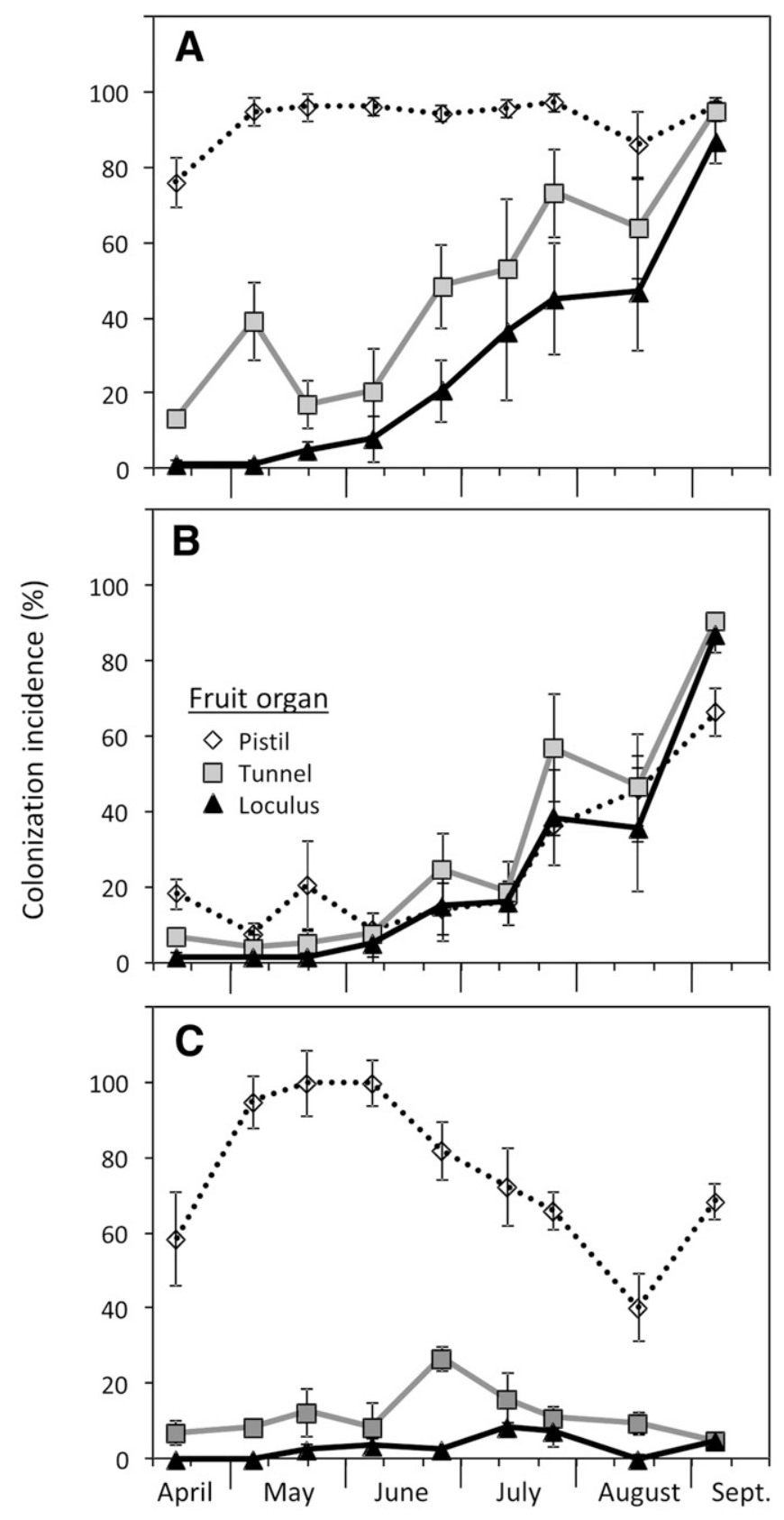

Month in 2010

Fig. 4. Dynamics of fruit-organ colonization by fungi during fruit development in 2010. A, Fungal colonization (by any species) of the pistil, the tunnel and the lower loculus. B, Colonization by Penicillium spp. of fruit organs. C, Colonization by Alternaria spp. of fruit organs. Vertical bars represent the standard error of the mean.
On the other hand, infection of the fruits by Penicillium followed the second of the suggested scenarios: isolation of this fungus from flowers and small fruits - growth stages 71 to 73-was very low, but there was a gradual rise in fungal isolation from fruits at growth stages 73 to 81 , and the increase continued as the fruits ripened. It is worth mentioning that no obvious symptoms attributable to the presence of this fungus were observed in the orchard or the laboratory performing Koch's postulates. Yet, it was previously reported that Penicillium spp. (P. glabrum, P. implicatum, and others) cause rot of the arils and the peel of stored pomegranate fruit (Bardas et al. 2009; Labuda et al. 2004; Palou et al. 2010, 2013). The internal rot was described as soft, brown tissue that became covered with green mycelium, while the calyx showed green conidiophores (Bardas et al. 2009). The Penicillium rot described in these studies resembles the collapse of arils and color change we observed in our attempt to
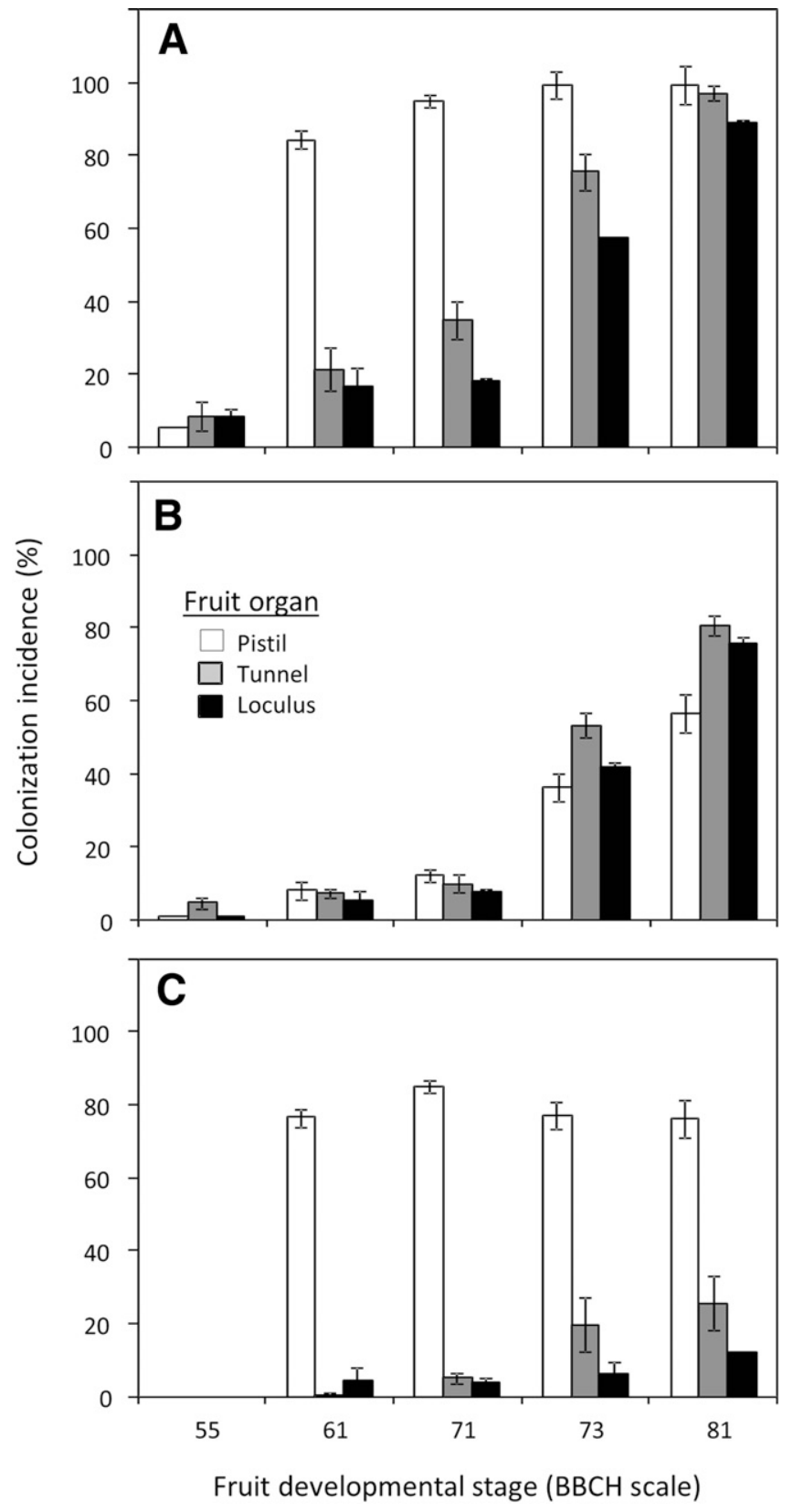

Fig. 5. Dynamics of fruit-organ colonization by fungi during fruit development in 2011. A, Fungal colonization by any species in the pistil, the tunnel, and the lower loculi. B, Colonization by Penicillium spp. of fruit organs. C, Colonization by Alternaria spp. of fruit organs. Fruit developmental stages according to $\mathrm{BBCH}$ General Scale: 51 = appearance of flower buds; $55=$ swollen calyx; $61=$ open flower; $71=$ young fruit; $73=$ fruit development; and $81=$ fruit ripening. Vertical bars represent the standard error of the mean. 
inoculate detached fruit with Penicillium spp. isolated from internal parts of fruit, still different from the black rot typical to heart rot caused by A. alternata in pomegranate both in texture and color.

The above discussion implies that suppression of heart rot incidence by preventing A. alternata from infecting the flowers (e.g., by application of fungicides) is impractical. The fungus penetrates its host through the stigmata and this is the plant organ to be protected by the fungicides. Directing fungicides to the stigmata of pomegranate flowers is a difficult task in view of the position of this organ in the developing flower and the erratic orientation of the flowers in the tree canopy. Furthermore, during the blooming period, new flowers open daily and flowers persist in the orchard for several weeks. This implies that fungicides, if deposited in the infection site (i.e., the stigmata), should be applied in short intervals for a long period of time. Indeed, attempts to suppress pomegranate heart rot in Israel by fungicide application resulted in insufficient results (I. Kosto, unpublished data) and this measure is no longer used by pomegranate growers.

Still unsolved is the question of why very few fruits developed rot whereas most of them were colonized with A. alternata and probably had the potential to develop the disease. It is possible that fruits located at different positions on the tree were exposed to slightly differing environmental conditions-e.g., sunlight, shade, etc.-and that these differences affect pathogen invasion and development. Differences in disease incidence may be explained by differences among cultivars as described by Palou et al. (2013) who found differences in Alternaria infection of cv. Wonderful vs. cv. Mollar de Elche growing in the same area in Spain (Palou et al. 2013). Yet, in our study we used commercial cultivars grown in Israel and among those we did not find fundamental differences in percent incidence of symptomatic fruits. Alternatively, it is possible those factors related to the host affect fruit physiology and that individual fruits differ in their susceptibility to pathogen invasion and rot development. This might happen, for example, if translocation of essential factors and elements were associated with fruit capability to resist disease development. Recently, it was demonstrated that the development of core rot caused by $A$. alternata in 'Red Delicious' apples was governed by host physiology rather than pathogen occurrence or environmental conditions at the bloom stage (Shtienberg 2012); it was found that the incidence of core rot was higher in light-yielding trees than in heavy-yielding ones and vice versa. The reasons for these findings are not yet known; however, light cropping in apple coincided with excessive shoot growth, increased fruit size, and lower fruit calcium concentration. The reduced calcium concentration in fruits growing on trees with excessive shoot growth has been attributed to stronger competition for available calcium between fruits, on the one hand, and vigorous new shoots with heavy foliage, on the other hand, at the most critical time for fruit development (Greene and Lord 1983). In heavy-cropping trees, fruits were usually relatively small but had high calcium concentrations which, on average, declined in inverse proportion to increasing fruit size; calcium concentration in apples from light-yielding trees was lower in all fruit-size classes than that in apples from trees with heavy crop loads (Sharples 1974; Shtienberg 2012). Calcium is considered to be an inhibitor of polygalacturonase, an enzyme produced by A. alternata during tissue invasion by the fungus. This enzyme, among other pectolytic enzymes produced by parasitic fungi including A. alternata, is needed by the fungus to promote rot development (Bateman and Lumsden 1965; Elad and Evensen 1995; Taiz and Zeiger 2002). These findings suggest that these correlations may be part of a possible explanation of the disease occurrence in apples; they also present a different aspect of the disease development and a possible role of plant physiology in pomegranate heart rot disease.

\section{Acknowledgments}

This work was financed by the Chief Scientist of The Ministry of Agriculture and Rural Development (MOARD) of Israel; grant number 132-1534-11. The authors would like to thank Mrs. Reoma Lambrez of the Ministry of Agriculture and Rural Development Extension Service for her assistance, and Ronen Ilel, Itzik Alfasi, Edi Benedicts, Mahamod Jorban, Gori Rozen, and Yaniv Aboksis for letting us use their orchards for these experiments. Contribution No. 536/13 from the Agricultural Research Organization, The Volcani Center, Bet Dagan, Israel.

\section{Literature Cited}

Ammar, M. I., and El-Naggar, M. A. 2014. Screening and characterization of fungi and their associated mycotoxins in some fruit crops. Inter. J. Adv. Res. 2 1216-1227.

Bardas, G. A., Tzelepis, G. D., Lotos, L., and Karaoglanidis, G. S. 2009. First report of Penicillium glabrum causing fruit rot of pomegranate (Punica granatum) in Greece. Plant Dis. 93:1347.

Bateman, D. F., and Lumsden, R. D. 1965. Relation of calcium content and nature of pectic substances in bean hypocotyls of different ages to susceptibility to an isolate of Rhizoctonia solani. Phytopathology 55:734-738.

Berbegal, M., López-Cortés, I., Salazar, D., Gramaje, D., Pérez-Sierra, A., GarcíaJiménez, J., and Armengol, J. 2014. First report of Alternaria black spot of pomegranate caused by Alternaria alternata in Spain. Plant Dis. 98:689.

Day, K. R., and Wilkins, E. D. 2009. Commercial pomegranate (Punica granatum L.) production in California. Acta Hortic. 890:275-286.

Elad, Y., and Evensen, K. 1995. Physiological aspects of resistance to Botrytis cinerea. Phytopathology 85:637-643.

Ezra, D., Gat, T., Skovorodnikova, Y., Vardi, Y., and Kosto, I. 2010. First report of Alternaria black spot of pomegranate caused by Alternaria alternata in Israel. Australas. Plant Dis. 5:1-2.

Gat, T., Liarzi, O., Skovorodnikova, Y., and Ezra, D. 2012. Characterization of Alternaria alternata causing black spot disease of pomegranate in Israel using a molecular marker. Plant Dis. 96:1513-1518.

Greene, D. W., and Lord, W. J. 1983. Effects of dormant pruning, summer pruning, scoring, and growth-regulators on growth, yield, and fruit-quality of Delicious and Cortland apple-trees. J. Am. Soc. Hortic. Sci. 108:590-595.

Holland, D., Hatib, K., and Bar-Ya'akov, I. 2009. Pomegranate: botany, horticulture, breeding. Hortic. Rev. (Am. Soc. Hortic. Sci.) 35:127-191.

Jayaprakasha, G. K., Negi, P. S., and Jena, B. S. 2006. Antimicrobial activities of pomegranate. Pages 167-183 in: Pomegranates: Ancient Roots to Modern Medicine. N. P. Seeram, R. N. Schulman, and D. Heber, eds. CRC Press Taylor \& Francis Group, Boca Raton, FL.

Labuda, R., Hudec, K., Piecková, E., Mezey, J., Bohovic, R., Mátéová, S., and Lukác, S. S. 2004. Penicillium implicatum causes a destructive rot of pomegranate fruits. Mycopathologia 157:217-223.

Levin, G. M. 2006:Pages 15-183 in: Pomegranate roads: a Soviet botanist's exile from Eden. B. L. Baer, ed. Floreat Press, Forestville, CA

Melgarejo, P., Martinez-Valero, R., Guillamon, J. M., Miro, M., and Amoros, A. 1997. Phenological stages of the pomegranate tree (Punica granatum L.). Ann. Appl. Biol. 130:135-140.

Michailides, T., Morgan, T., Quist, M., and Reyes, H. 2008. Infection of pomegranate by Alternaria spp. causing black heart. Phytopathology 98: S105.

Pala, H., Tatli, A., Yilmaz, C., and Özgüven, A. I. 2009. Important diseases of pomegranate fruit and control possibilities in Turkey. Acta Hortic. 818 285-290.

Palou, L., Guardado, A., and Montesinos-Herrero, C. 2010. First report of Penicillium spp. and Pilidiella granati causing postharvest fruit rot of pomegranate in Spain. New Dis. Rep. 22:21

Palou, L., Taberner, V., Guardado, A., del Río, M. A., and Montesinos-Herrero, C 2013. Incidence and etiology of postharvest fungal diseases of pomegranate (Punica granatum cv. Mollar de Elche) in Spain. Phytopathol. Mediterr. 52: 478-489.

Seeram, N. P., Zhang, Y., Reed, J. D., Krueger, C. G., and Vaya, J. 2006 Pomegranate phytochemicals. Pages 3-29 in: Pomegranates: Ancient Roots to Modern Medicine. N. P. Seeram, R. N. Schulman, and D. Heber, eds. CRC Press Taylor \& Francis Group, Boca Raton, FL.

Sharples, R. O. 1974. The number and size of fruits in relation to rootstock type, application of growth regulators, pruning, and fruit thinning. Acta Hortic. 45: $21-24$

Shtienberg, D. 2012. Effects of host physiology on the development of core rot caused by Alternaria alternata, in Red Delicious apples. Phytopathology 102:769-778.

Taiz, L., and Zeiger, E. 2002. Mineral nutrition. Pages 67-86. in: Plant Physiology, 3rd Ed., Taiz, L., and Zeiger, E., eds. Sinauer Associates, Inc., Sunderland, MA.

Tziros, G. T., Lagopodi, A. L., and Tzavella-Klonari, K. 2008. Alternaria alternata fruit rot of pomegranate (Punica granatum) in Greece. Plant Pathol. 57:379.

Zhang, L., and McCarthy, M. J. 2012. Black heart characterization and detection in pomegranate using NMR relaxometry and MR imaging. Postharvest Biol. Technol. 67:96-101. 